\title{
O Adolescente e o Processo de Hospitalização: a psicologia construindo possibilidades
}

\author{
The Teenager and the Hospitalization process: psychology building possibilities
}

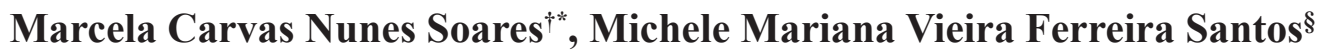

Como citar esse artigo. Soares, M.C.N.; Santos, M.M.V.F. O Adolescente e o Processo de Hospitalização: a psicologia construindo possibilidades. Revista Mosaico, v.11, n.2, p. 101 - 108, 2020.

Nota da Editora. Os artigos publicados na Revista Mosaico são de responsabilidade de seus autores. As informações neles contidas, bem como as opiniões emitidas, não representam pontos de vista da Universidade de Vassouras ou de suas Revistas.

\begin{abstract}
Resumo
O presente trabalho objetiva demonstrar o impacto do processo de hospitalização para adolescentes, bem como em sua família e, até mesmo, à equipe multiprofissional que atuará com esse paciente, através de um estudo bibliográfico. Compreender as vivências, mudanças dessa etapa do ciclo vital - adolescência - e as transformações que a doença/internação traz aos sujeitos que experienciam esse momento, são de suma importância para que os profissionais possam atuar diante desse público. A partir deste, procura-se também, evidenciar o trabalho do psicólogo junto aos adolescentes no contexto hospitalar, visando acolher as demandas que possam apresentar sobre o processo saúde-doença, buscando, conjuntamente com seus protagonistas, maneiras de amenizar o sofrimento advindo com este cenário. Pôde-se observar através deste estudo que se faz necessária a criação de áreas de internação que visem a clientela adolescente, trazendo, assim, benefícios ao cuidado desses pacientes e mais conhecimento teórico-prático no que concerne à saúde juvenil.
\end{abstract}

Palavras-chave: Atuação do Psicólogo, Adolescente, Hospitalização.

\begin{abstract}
This work aims to demonstrate the impact of the hospitalization process for adolescents as well as their family and even the multiprofessional team that will work with this patient, through a bibliographic study. Understanding the experiences, changes of this vital cycle - adolescence - and the transformations that the illness/internal care brings to the subjects who experience this moment are of utmost importance for the professionals to act before this public. From this moment on, we also try to highlight the work of the psychologist with the adolescents in the hospital context, aiming to welcome the demands they may present about the health-disease process, seeking, together with their protagonists, ways to alleviate the suffering arising from this scenario. It was possible to observe trough this study that it is necessary to create areas of hospitalization that target the adolescent clientele, thus briging benefits to the care of these patients and more theoretical and practical knowledge regarding youth health.

Keywords: Psychologist's Performance, Adolescent, Hospitalization.
\end{abstract}

Abordar-se-á, neste estudo, a etapa do ciclo vital da adolescência no contexto de internação hospitalar, buscando compreenderahistoricidadee as peculiaridades vivenciadas por tal faixa etária, relacionando-a a situações e implicações acometidas pela hospitalização, através de verificação bibliográfica.

No decorrer do tempo, a apreciação sobre a adolescência sofreu inúmeras modificações, além de possuir conceitos diferentes em diversas culturas. Contudo, é preciso considerar que esta etapa da vida, como propõe Alberti (2009), é demarcada também por diversas perdas e lutos como, por exemplo, o luto pelo corpo infantil, além, de como indica Aberastury (1981), da possibilidade/necessidade de separação dos pais.

Uma situação de doença pode acarretar um rompimento do equilíbrio vital e, com a hospitalização, ocasionar alterações na vivência, tanto do paciente quanto de seus familiares e, como propõe Chiattone (2003) tais situações poderiam causar ainda prejuízos relacionados à noção de identidade, sendo peculiar a cada faixa etária.

Segundo Santos e Sebastiani (2003), a internação em hospital força uma condição de dependência e é preciso considerar que, justamente na adolescência, o sujeito busca se desvencilhar e começar a tornarse independente, com necessidades e especificidades

Afiliação dos autores:

† Pós-graduanda, curso de Psicologia Hospitalar e da Saúde, Universidade de Vassouras, Vassouras, RJ, Brasil.

$\S$ Professora e Pesquisadora do Curso de Psicologia da Universidade de Vassouras, Vassouras, RJ, Brasil. 
próprias, demonstrando, com isso, mais um agravo relacionado ao processo de internação.

$\mathrm{Na}$ adolescência, como discorre Aberastury et al. (1981, p.26), acontece um processo de reconstrução, aceitação e reconhecimento do novo corpo; a hospitalização, nesse sentido, é passível de ocasionar danos a este processo, visto que, na internação, o corpo é, em diversos momentos, manipulado pelos profissionais da saúde e invadido pelos procedimentos necessários, como aplicação de medicamentos, exames e dietas, entre outros.

Para tanto, objetiva-se esboçar a importância da atuação do psicólogo junto ao paciente adolescente e seus familiares frente ao processo saúde-doença, no diagnóstico, tratamento e hospitalização, buscando, a partir da Psicologia, ofertar escuta qualificada, assistência e possibilidades de enfrentamento do momento vivenciado na internação.

Contudo, podemos analisar, mediante às apreciações deste trabalho, a importância em se pensar em alas de internação específicas ao público adolescente, corroborando, desta forma, com o cuidado de pacientes desta faixa etária, bem como com estudos e práticas da atuação do profissionais em relação à saúde na adolescência.

\section{A Adolescência}

De acordo com Ariès (1986) o termo adolescência surgiu apenas no século XVIII. Anteriormente, não havia distinção entre mundo infantil e adulto. Saggese (2001, p. 61) discorre que o adolescente vai se delimitando como "um mundo à parte [...] jovens que buscam, conflitivamente, uma definição singular e única para suas vidas".

É na fase da adolescência que o sujeito percebe a falta do real, bem como sua incompletude e diversas perdas e lutos, próprios da faixa etária, como o desaparecimento do corpo de criança e a separação dos pais. Alberti (2010, p.10) propõe, então, que o adolescente tem "um longo trabalho de escolhas" assumindo ou não as decisões de seus familiares - e "um longo trabalho da falta do Outro" - presente desde o nascimento. Porém, nessa etapa, busca encontrar substitutivos para demarcar sua existência, percebendo a possibilidade de assumir seus desejos e de estabelecer novas identificações e grupos de convívio além do familiar.

Contudo, apesar de a adolescência ser marcada pela transição da vida em família para um círculo social mais ampliado, o sujeito nesse período ainda demanda bastante de seus pais; dessa forma, a presença familiar se faz importante nesse processo de separação e escolhas. Ainda é possível preponderar que é nesse período que dá início às suas experiências "como autor de um desejo"
(ALBERTI, 2010, p.16).

Para a Psicanálise, o adolescente transpassa as identificações imaginárias (onde busca ser merecedor do Outro ) e busca fazer sua integração a partir de identificações simbólicas (onde avalia ser merecedor do Outro). Com essa nova visão, é possível acarretar ao sujeitoadolescenteestigmasadvindos dastransformações físicas e psíquicas próprias das mudanças desse período, o qual sente ser exigido pela sociedade. No entanto, serão essas assimilações que o constituirão, surgindo, com isso, a crise da adolescência.

As relações estabelecidas por um sujeito são, portanto, delimitadas pelo Outro, inclusive considerando o campo do conhecimento; assim, de acordo com Alberti (2010), o adolescente já reconhecendo-se como um ser faltoso, ele estabelece que não existe um saber absoluto, com isso, então, podem surgir inúmeras decisões, desde não realizar uma tarefa escolar até escolher uma profissão.

Torna-se importante, também, colocar que se o sujeito adolescente não consegue reconhecer a falta inerente ao ser humano, pode desenvolver um quadro de depressão, tendo dificuldades em estabelecer relações simbólicas para assumir suas decisões e responsabilidades. Alberti (2010, p. 42), coloca a depressão como "uma baixa energia psíquica, que aparece em um momento em que o eu evita sua determinação $[. .$.$] ".$

A partir de tais apreciações sobre o adolescer, poderemos colocá-lo diante de um processo de hospitalização.

\section{A Hospitalização}

Considerando um breve histórico, inicialmente, muitas instituições antigas que cuidavam de patologias eram de cunho religioso (mosteiros, templos etc.) e se localizavam em lugares favoráveis ao restabelecimento da saúde, como nos altos das montanhas, próximos às florestas e de fontes de água mineral. Os cuidados, por sua vez, eram impregnados de misticismo. "A influência religiosa foi predominante, sobretudo na Idade Média. $\mathrm{O}$ corpo humano, feito à imagem de Deus, não podia ser aberto: era sacrilégio. Só a alma precisava de tratamento." (BRASIL, 1944, p. 29).

No Brasil, por ter sido colônia de Portugal, a preocupação com os doentes veio junto com a colonização. O hospital brasileiro mais antigo é a Santa Casa de Santos, fundada em 1533 por Braz Cubas. Mas, somente no século XVIII, com o auxílio de alguns pesquisadores da medicina, houve grande progresso nessa área; com isso, no século seguinte, foi possível que surgissem hospitais com o layout contemporâneo. (BRASIL, 1944, p. 55)

Primeiramente, os saberes dos profissionais 
que atuavam nessas instituições eram mais voltados aos doentes do que às doenças; porém, ao longo do tempo, com as experiências, pesquisas e tecnologias que foram surgindo voltaram-se para as patologias. Foucault (1996) relata que o crescimento e a valorização médica nos hospitais ocorrem quando estes passam a ser locais de cura, a partir do momento em que a sociedade vê o corpo do homem como investimento e força de trabalho e, por esse motivo, necessita ser recuperado.

Nas instituições hospitalares modernas, atualmente, podemos encontrar um imenso aparato tecnológico utilizado para diagnosticar e tratar seus pacientes, tornando-se assim também centros de pesquisa e ensino. Os hospitais puderam, em momentos diversos da evolução dessa instituição, se debruçar sobre a prática desenvolvida, inicialmente curativa, em seguida preventiva e, posteriormente, atuando em todos os serviços de saúde, desde a prevenção até a reabilitação, sendo seus cuidados voltados à toda a população (CAMPOS, 1995, p. 20).

A Organização Mundial da Saúde, por sua vez, define o conceito de hospital como:

Parte integrante de um sistema coordenado de saúde, cuja função é dispensar à comunidade completa assistência médica, preventiva e curativa, incluindo serviços extensivos à sua família em seu domicílio e ainda um centro de formação dos que trabalham no campo da saúde e para as pesquisas biossociais. (PINHEIRO, 2005, p. 2). sendo:

Já o Ministério da Saúde, aprecia hospital

Parte integrante de uma organização médica e social, cuja função básica consiste em proporcionar à população assistência médico-sanitária completa, tanto curativa como preventiva, sob quaisquer regimes de atendimento, inclusive o domiciliar, e cujos serviços externos irradiam até o âmbito familiar, constituindo-se também em centro de educação, capacitação de recursos humanos e de pesquisas em saúde, bem como de encaminhamentos de pacientes, cabendolhe supervisionar e orientar os estabelecimentos de saúde a ele vinculados tecnicamente. (BRASIL, 1977, p. 9).

Como podemos perceber na obra de Campos (1995), a função do hospital também é social, em relação a comunidade na qual está inserido. Além ainda de, como abrange Lima Gonçalves (citado por CAMPOS, 1995, p. 21) "o hospital reflete de certo modo a humanidade", ao ponto de acolher as angústias, as dificuldades, os desejos, as alegrias e outros sentimentos demonstrados por pacientes, familiares e profissionais que estão em contato com a instituição.

Campos (1995) coloca que a internação e a perda da autonomia do sujeito hospitalizado estão ligadas ao modo que o hospital se interpõe em relação à essas questões, "dependendo da instituição, de sua filosofia de ação, da prática que os funcionários de todos os níveis tenham, no tocante à vivência humanizante ou opressora da pessoa hospitalizada" (CAMPOS, 1995, p. 31).

A hospitalização, então, pode ser compreendida a partir de um indivíduo ser admitido e permanecer em um estabelecimento hospitalar, público ou privado, que tenha recursos para o tratamento de pessoas adoecidas. Esse processo pode interferir positiva ou negativamente em toda a aceitação do paciente ao seu tratamento, de acordo com a maneira em que ele for acolhido pela equipe da instituição.

\section{O Adolescente e a Doença que Necessita de Internação}

Anteriormente, já se preponderou sobre a adolescência neste trabalho. Nesse tópico, por sua vez, buscar-se-á inter-relacionar essa etapa do ciclo vital com o adoecimento/hospitalização.

Especificar a adolescência nos estudos é algo feito mais recentemente, a partir do século XX; com isso, por vezes, é difícil encontrar dados científicos em relação a essa etapa do ciclo vital. Queiroz et al. (2013), nos informa que em 1911 G. Stanley Hall, faz uma publicação envolvendo essa faixa etária; posteriormente, nas décadas de 1940 e 1950, médicos passaram a fazer avaliações com adolescentes quanto ao crescimento e desenvolvimento. Contudo, apenas com o fim da Segunda Guerra Mundial é que a saúde desse público se tornou uma preocupação da sociedade, onde estes apresentavam enfermidades crônicas, transtornos psicossociais, dependência de fármacos e gravidez na adolescência.

Como visto, é na adolescência que o sujeito começa a se desvencilhar dos familiares e a inserir-se em outros grupos sociais. Porém, tratando-se de um sujeito adolescente hospitalizado, é imprescindível a presença das figuras de seus familiares, sobretudo seus pais, pois estes representam sua conexão com a vida normal, como coloca Sônia Alberti em perspectiva de uma de suas pacientes:

[...] toda cirurgia é sempre vivida como ameaçadora- ao qual estava completamente submetida, sem nem mesmo o recurso para uma transferência apaziguadora, que muitas vezes se dá através da presença dos pais no momento préoperatório, razão da importância da presença dos pais junto ao adolescente hospitalizado. (ALBERTI, 2010, p. 49)

A presença desses pais/responsáveis no ambiente hospitalar corrobora a participação destes nos cuidados básicos de seus entes, desenvolvendo ações conjuntas com os profissionais de saúde. Por outro lado, essa presença também modifica a rotina dos serviços de saúde e dos profissionais que ali agem. De acordo com Almeida e Sabatés (2003), onde antes o cuidado era focado na doença, passa-se a cuidar do paciente e do 
familiar, que requer o atendimento às suas necessidades, como informações e participação no cuidado durante e após a internação.

Historicamente, é perceptível que as pessoas sempre buscaram lutar contra a doença/morte, onde patologias são combatidas com medicamentos e tratamentos diversos. A doença modifica a rotina do sujeito adoecido, sendo sentida de maneira singular por cada indivíduo. $\mathrm{O}$ processo de adoecimento traz consigo um rompimento do equilíbrio vital, que pode se agravar com a hospitalização, pois pode acarretar condição de dependência, prejudicar a identidade, a autonomia, desencadear depressão, regressão etc. Dessa forma, mesmo que a doença manifestada seja física, ela se demonstrará também no campo psíquico, podendo aparecer, com isso, desequilíbrios psicológicos tanto no paciente quanto nos familiares.

Em estados de estresse ou depressão, o organismo perde a capacidade de reconhecer e anular células malignas mutantes que passam a se reproduzir livremente. Esse é um dos motivos pelos quais quando o sentimento de culpa é muito intenso, é necessária ajuda psicológica para evitar que o estado emocional impeça de responder positivamente ao tratamento [...] Na situação de doença, internação, cirurgia, a intensa ansiedade é capaz de desencadear comportamentos regredidos [...] A regressão é natural, muitas vezes incentivada pelos familiares, que ansiosos e culpados, mimam e superprotegem o doente. (FREITAS, 1980 citado por CAMPOS, 1995, p. 45)

Foucault (1975) se refere à doença relacionando-a ao indivíduo como um todo, psicológica e fisiologicamente, estabelecendo, assim, uma interrelação entre corpo e mente, devendo ser considerados fatores tanto internos quanto externos; sendo assim, a saúde é um processo que buscamos e adquirimos em todos os momentos da vida, como algo contínuo.

Ao relacionar paciente-internação, Campos (1995) demonstra que pacientes e familiares anseiam por organização da instituição hospitalar, bem como o restabelecimento de sua saúde; sendo assim, os profissionais que atuam no hospital devem também suprir diversos outros quesitos além do ambiente, como uma educação sanitária e reintegração à comunidade.

Noprocessodehospitalizaçãosãodesencadeadas diversas emoções, que são sentidas independentemente da idade do sujeito internado, pois este ambiente demonstra ser repleto de agentes estressores. Porém, na adolescência pode ser vivenciado de forma exacerbada pelos próprios conflitos dessa etapa do ciclo vital e este adolescente pode sentir-se ameaçado pela doença/ internação remeter-lhe à morte, além de limitá-lo ao convívio dos amigos e familiares. (GUZMAN; CANO, 2000).

O serviço de saúde, de acordo com Guzman e Cano (2000), seja da rede privada ou pública, não tende a oferecer unidades de atendimento próprias para adolescentes, acontecendo muitas vezes em enfermarias pediátricas ou adultas, o que pode dificultar ainda mais a adaptação deste paciente à esse cenário. Sendo assim, uma unidade específica para a adolescência, com equipe multidisciplinarcapacitada às especificidades dessa faixa etária, seria necessária para que a hospitalização não seja um entrave no desenvolvimento desse paciente.

O Estatuto da Criança e do Adolescente (ECA) (BRASIL, 1990), legislação reguladora de direitos e deveres da infância e da adolescência, traz informações necessárias e importantes. Considerando situações de saúde para adolescentes, podemos identificar no ECA quando discorre sobre "Direito à Vida e à Saúde", no art. $7^{\circ}$, por exemplo, que "a criança e o adolescente têm direito a proteção à vida e à saúde, mediante a efetivação de políticas sociais públicas [...]"; já em seu art. 11º, prepondera sobre a oferta de saúde para esse público específico, onde deve ser "assegurado atendimento integral à saúde da criança e do adolescente, por intermédio do Sistema Único de Saúde, garantido o acesso universal e igualitário [...]"; ainda podemos considerar o art.12 $2^{\circ}$, onde "os estabelecimentos de atendimento à saúde deverão proporcionar condições para a permanência em tempo integral de um dos pais ou responsável [...]". Posteriormente, faz ponderações sobre "Liberdade, Responsabilidade e Dignidade", em seu art. $16^{\circ}$ que abrange os aspectos da liberdade aos quais os adolescentes têm direito; no art. $17^{\circ}$, pensandose no contexto de internação hospitalar: "inviolabilidade da integridade física, psíquica e moral da criança e do adolescente, abrangendo a preservação da imagem, da identidade, da autonomia, dos valores, ideias e crenças, dos espaços e objetos pessoais."; já no art.18º "é dever de todos velar pela dignidade da criança e do adolescente, pondo-os a salvo de qualquer tratamento desumano, violento, aterrorizante, vexatório ou constrangedor". Em seguida, ao relatar sobre o "Direito de Convivência Familiar e Comunitária", podemos observar no art. $21^{\circ}$, que "o poder familiar será exercido, em igualdade de condições, pelo pai e pela mãe, na forma do que dispuser a legislação civil [...]". Por fim, neste documento, ainda se referencia aos direitos à educação, cultura, espaço e lazer.

O ECA assegura às crianças e adolescentes hospitalizados o direito à um acompanhante durante o período de internação em seu art.12 $2^{\circ}$, porém, muitas vezes isso lhes é negado, por empecilhos como um espaço físico inapropriado. A presença desse familiar durante o processo de internação, além de ser um direito legítimo, é também uma necessidade diante de todos os efeitos que o cenário hospitalar traz para um adolescente adoecido.

Foi o ECA que trouxe muitas modificações no que concerne aos direitos e deveres relacionados às crianças e aos adolescentes, os quais deixaram de ser objetos de intervenções e passaram a ser inseridos 
em um contexto de cidadania. De acordo com Cury (2013), essa legislação foi bastante significativa para a sociedade, alterando a noção que se tinha dessas faixas etárias, além de influenciar no funcionamento das instituições, sejam escolas, hospitais, abrigos etc.

Além do ECA, temos também a Constituição Federal de 1988 (BRASIL, 1988) como fundamental à proteção dos direitos de crianças e adolescentes, reconhecendo-os como seres com especificidades de desenvolvimento, legitimando a diferença entre o universo adulto e infantil. Reconhece também as vulnerabilidades em que podem estar expostos e, ainda, as suas potencialidades. No artigo 227 da Constituição/1988 pode-se ler:

É dever da família, da sociedade e do Estado assegurar à criança e ao adolescente, com absoluta prioridade, o direito à vida, à saúde, à alimentação, à educação, ao lazer, à profissionalização, à cultura, à dignidade, ao respeito, à liberdade e à convivência familiar e comunitária, além de colocá-los à salvo de toda forma de negligência, discriminação, exploração, violência, crueldade e opressão. (BRASIL, 1988, p. 132)

Considerando a legislação para menores de idade em situação de hospitalização, temos ainda a Resolução $\mathrm{n}^{\circ}$ 41, de 1995 (BRASIL, 1995), dos Direitos das Crianças e Adolescentes Hospitalizados, formulada pela Sociedade Brasileira de Pediatria. Nesse documento, coloca-se o "direito a que seus pais e responsáveis participem ativamente do diagnóstico, tratamento e prognóstico, recebendo informações sobre os procedimentos a que será submetida".

Essas legislações que enfatizam o período de infância e da adolescência também trazem exigências quanto às instituições que atendem esse público, o que inclui os hospitais. Abordando, contudo, o contexto hospitalar, como já mencionado, não há implementação de peculiaridades que atendam o público adolescente, em um geral. Adorno (1993 citado por CACHAPUZ, 2006) expõe que a visão dos profissionais acerca de sua prática pode contribuir para a formulação e implantação dessas distinções para os adolescentes. Saraiva (2003 citado por CACHAPUZ, 2006) nos coloca ainda, que a conquista de direitos e deveres para as crianças e adolescentes foi gradual, necessitando até hoje de questionamentos e debates.

De acordo com Honicky e Silva (2009), os adolescentes apresentam o desejo de serem ativos e considerados em suas especificidades no ambiente hospitalar; além disso, esse paciente tem o direito de conhecer seu diagnóstico, prognóstico e tratamento e é obrigação dos profissionais da instituição fornecer as informações de maneira clara e objetiva. Como a fase da adolescência é considerada, de acordo com o ECA, dos 12 aos 18 anos incompletos, sendo assim, seu responsável legal é quem deve tomar ciência sobre questões relevantes; contudo, muitas vezes, essa família omite os dados desse adolescente adoentado/ hospitalizado.

Com relação à informação, é preciso pensar também em comunicação, pois o receptor (no caso de adolescentes, em sua maioria será o responsável que receberá as notícias) pode não compreender. Para dar clareza às informações é necessário que o profissional utilize todos os meios disponíveis além da fala, do uso de um discurso técnico. É preciso que haja um diálogo com trocas de dúvidas e esclarecimentos, mesmo que careça de esquemas e desenhos.

Para minimizar o sofrimento advindo com a vivência em hospital, segundo Almeida et al. (2007, p. 36), os adolescentes podem apresentar "atitudes compensatórias e permissivas", para que assim possam diminuir a culpa que sentem por tal processo.

$\mathrm{O}$ grupo extra-familiar com o qual o adolescente interage pode transmitir à ele sensação de segurança, pelas identificações em comum, como o vocabulário, roupas, preferências musicais etc.; mas quando este adolescente adoece, acontece o contrário, e este mesmo grupo the confere insegurança, conjuntamente com um brusco afastamento desses pares. Assim, este sujeito, retirado do convívio com os amigos e afastado do ambiente escolar, pode desencadear sentimentos dolorosos, angustiantes e tristes, diante dessa condição, o que pode gerar, ainda, raiva, ciúmes e ansiedades (ARMOND, 1996 citado por HONICKY; SILVA, 2009).

Uma possibilidade para o jovem perpassar pelo momento de hospitalização/doença é a convivência com seus pares, ou seja, jovens de mesma faixa etária, para a construção de sua individualidade, apesar do contexto em que está inserido. Porém, a rotina do sistema hospitalar e o pouco estudo correlacionado à temática de adolescente e hospitalização para embasamento dos profissionais que atuam com esse público acaba acarretando dificuldades nesse processo, atrapalhando, com isso, a consolidação de sua identidade e independência, típicos da adolescência. No entanto, um dos profissionais da equipe hospitalar que pode atuar junto a esse sujeito adolescente hospitalizado para amenizar as dificuldades desse cenário é o psicólogo.

\section{A Atuação do Psicólogo junto Adolescente Hospitalizado}

Os diversos profissionais que atuam no ambiente hospitalar desempenham papéis específicos. Contudo, aqui enfocaremos o psicólogo dentro do hospital e seu manejo com adolescentes, que age preponderando os aspectos clínicos, sociais, educacionais, mediante a saúde considerada como algo que engloba múltiplos setores. No atendimento à essa faixa etária deve-se 
considerar não somente questões de saúde e demandas psicológicas, mas também as diretrizes próprias para esse público, norteando o trabalho a ser desenvolvido com eles.

Burd (2006) coloca que a relação que o paciente e sua família estabelecem com a equipe de saúde é de suma importância para o tratamento. Assim, esses profissionais podem criar condições para que o paciente reflita sobre seu adoecer, de maneira singular a cada vivência.

[...] atendimento de um profissional da saúde busca responder a uma angústia, um pedido de ajuda e de socorro. É o cliente que sabe dimensionar a sua dor e sua angústia. Assim, as respostas do profissional da saúde não podem ser respostas padronizadas e uniformes, que nem sempre estabelecem a integração necessária entre ele e quem recebe seus cuidados. (CAMPOS, 1995, p. 61)

O psicólogo e outros profissionais que trabalham no ambiente hospitalar atuam justamente auxiliando o paciente a se adequar à rotina do hospital, pois este contexto tende a romper a interação desse sujeito com a sociedade, família, amigos e escola, entre outros espaços de convivência. Além disso, é importante também observar e reconhecer as peculiaridades que cada paciente manifesta no decorrer de sua internação, como expectativas sobre a alta hospitalar, o tratamento, a visita de familiares e amigos, o significado da doença e da internação, entre outros. O profissional deve, assim, se preparar para atender as demandas do paciente sobre as dúvidas que pode ter deste processo que está experienciando, considerando os aspectos físicos, psíquicos, emocionais, sociais, econômicos e espirituais, dando suporte, considerando, sobretudo, a subjetividade do outro, respeitando o desejo ou não de o paciente receber assistência psicológica.

A Psicologia Hospitalar no Brasil é um desdobramento da Psicologia da Saúde, além disso, o termo Psicologia Hospitalar não existe em outros países, porém essa nomenclatura traz maiores especificidades à atuação do profissional nesse âmbito: "[...] a Psicologia Hospitalar é o campo de entendimento e tratamento dos aspectos psicológicos em torno do adoecimento" (SIMONETTI, 2004, p. 15).

A Psicologia Hospitalar, nesse cenário, utiliza conhecimentos de áreas diversas do saber psicológico; além da Psicologia Clínica, comunica-se com as áreas Organizacional, Educacional e Social, sendo sua prática ligada às necessidades de cada paciente, considerando a demanda da doença e/ou da internação.

Nessa prática, o profissional psicólogo, pode utilizar como ferramenta um roteiro de avaliação psicológica, voltado às especificidades da hospitalização/ adoecimento, que, como expõe Fongaro e Sebastiani (2003, p. 6), pode "trazer dados do paciente de forma objetiva ao psicólogo e equipe de saúde". Esse roteiro, então, é composto por algumas funções: diagnosticar, orientar o foco, fornecer dados sobre a psicodinâmica do paciente, ser instrumento de avaliação continuada do processo evolutivo da relação do paciente com seu tratamento/doença, história da pessoa, possibilitar diagnóstico diferencial quanto à quadros psicológicos e/ou psiquiátricos específicos, estabelecer relações da pessoa com seu prognóstico. O roteiro de avaliação psicológica pode, ainda, ter função terapêutica, pois possibilita que o paciente se manifeste, questione e reflita sobre sua condição.

Ao considerar o exposto acima, é bem possível ponderar sobre a relevância da Psicologia nesse cenário de promoção da saúde, seja em âmbito da prevenção como no tratamento. Campos (1995, p. 67) "aponta que o psicólogo, além de diagnosticar e classificar, tem de entender, compreender o que está envolvido na queixa e no sintoma, na patologia". Com isso, esse profissional deve valorizar o sujeito, suas angústias, medos, enfrentamentos advindos do contexto que está vivenciando, podendo explanar seus sentimentos acerca do adoecimento e não somente a doença em si - função que muitos outros já desempenharam.

[...] a pessoa necessita falar de sua doença, do assunto que parece ser proibido. Parece que a pessoa não precisa de distração, mas precisa de compreensão e da possibilidade de exprimir suas angústias, seus medos, tocando diretamente no assunto, na história da doença. (FREITAS, 1980, citado por CAMPOS, 1995, p. 69)

O objetivo, portanto, do psicólogo hospitalar é atuar considerando o processo saúde-doença vivenciado pelopaciente, acolhendonão somente a pessoaadoentada, mas também sua família e a equipe, oferecendo apoio psicológico, para, desta forma, minimizar o sofrimento a que estas personagens estão submetidas por conta da doença. O psicólogo, nesse contexto, pode também mediar as relações entre equipe-paciente, equipe-família e até paciente-família. Com o auxílio deste profissional, também poderão compartilhar seus limites, suas dificuldades, seus medos, dependências, impotências, sentimento de culpa, negação da realidade e dificuldade em adaptar-se à rotina hospitalar.

Pode-se considerar de bastante importância, ainda, a atuação do psicólogo junto aos pacientes em relação à imagem corporal diante da hospitalização/ doença, pois este aspecto pode sofrer alterações tanto por conta da patologia quanto por ter restrição e imposição à certas atividades e alimentos, dietas, tratamento medicamentoso, intervenção cirúrgica, vestimenta padronizada, falta de privacidade, horários pré-estabelecidos e a própria hospitalização. Guzman e Cano (2000) expõem, então, que o adolescente, impregnado por tantas regras, tende a entrar em conflito com as normas, burlando-as e desafiando-as. Além disso, pode demonstrar desinteresse em seu tratamento. 
Cada sujeito elabora sua autoimagem, mas, ao se considerar a etapa da adolescência, é possível ponderar sobre questionamentos próprios da idade relacionados ao corpo. $\mathrm{O}$ adolescente pode vivenciar a hospitalização como perda, ruptura, separação ou mudança de suas referências, prejudicando sua noção de identidade e imagem corporal. Ambrós (2004, citado por HONICKY; SILVA, 2009), coloca que a despersonalização leva à descontinuidade na percepção da vida, rompendo assim com a sua história, que até então, para ele era coerente e organizada.

$\mathrm{Na}$ adolescência é possível perceber sentimentos de onipotência e intensidade, onde esse sujeito se considera, por diversas vezes, independente das experiências e conselhos dados por pessoas mais velhas de seu círculo de convivência. Mas, considerando situações de risco, como por exemplo, o adoecimento e a hospitalização, o adolescente emerge em sentimentos que contradizem àquele caráter de onipotência, trazendo mecanismos de defesa e fantasia. Chiatone (2003) relata efeitos de negação, revolta, culpa, punição, ansiedade, depressão, projeção, solidão e regressão emocional.

Nigro (2004) ressalta que o processo de internação desencadeia medo, receio pelo desconhecido, onde as fantasias relacionadas ao ambiente hospitalar remetem ao abandono, perda e solidão, sentimentos estes já exacerbados na adolescência, o que pode traumatizar o sujeito e levar a uma piora em seu quadro clínico. A partir deste ponto, a autora enfatiza a importância da assistência psicológica, a possibilidade de fala e compreensão das experiências vividas nesse contexto, auxiliando o paciente adolescente a ressignificar sua doença e hospitalização, de forma a refletir sobre seus sentimentos diante da patologia e possibilidades de colaboração com o tratamento/recuperação.

Quando finalmente convidamos o sujeito adolescente a falar, aquilo que se tornará uma questão para ele muito dificilmente condiz com a queixa dos pais e/ou técnicos. Então muitas vezes é preciso tranquilizar os pais com relação à angústia frente ao adolescer do filho, por um lado e, por outro lado, seguir à risca o dito freudiano segundo o qual a psicanálise não deve visar a remissão dos sintomas, mas o tratamento do sujeito, com sua história, suas questões e dificuldades, no caso, do próprio adolescente. (ALBERTI, 2009, p.32)

$\mathrm{O}$ adoecimento pode gerar diversas reações, como já mencionado. Com a negação, por exemplo, adolescentes adoecidos podem descartar a medicação, não realizar a dieta estabelecida e se recusar aos procedimentos de tratamento. Ao confrontar essa nova realidade, esse tipo de reação do adolescente pode ser minimizada através de fantasias sobre seu estado de saúde, dificultando sua verdadeira compreensão do problema. Pois, através do imaginário, este jovem cria ou faz alusão à um fato diferente ao vivenciado que, ao mesmo tempo que o auxilia a transpor esse período, o transfere para algo que não é real, podendo interferir no tratamento.

Contudo, alguns adolescentes percebem a hospitalização como algo bom, no sentido de estar sendo amparado e afastado de um contexto social impregnado de vulnerabilidades, tais como violência, fome e famílias desestruturadas, entre outros.

A hospitalização, segundo Nigro (2004), é um processo vivenciado não só pelo paciente, mas também por sua família, trazendo alterações em todo o contexto familiar, pois esta vivência é extremamente significativa, estranha e impactante.

A clínica com adolescentes é um excelente campo para a verificação desse fenômeno e muitas vezes exige aintervenção do analista junto à família no sentido de fazer valer o pai que já não se crê capaz de ser ouvido, valorizado ou levado em conta. (ALBERTI, 2004, p. 21)

Mesmo os adolescentes tendo direitos certificados por Políticas Públicas de Saúde, próprias à sua faixa etária, é perceptível que teoria e prática ainda estão bastante distantes, dado que muitos não têm assegurados os princípios de universalidade, integralidade e equidade no acesso aos serviços de saúde. Considerando o Sistema Único de Saúde SUS, por exemplo, Cecílio e Merhy (2003, citado por CACHAPUZ, 2006, p. 45) levantam críticas relacionadas à noção de um sistema em harmonia que é propagado, visto que o sistema de saúde é plural e demonstra mobilidade, assimetria e incompletude em seus serviços. Esses autores ainda enfocam que uma problemática desta forma de funcionamento é a dificuldade em se atingir a integralidade, uma das noções norteadoras do serviço e para que ela aconteça é preciso que os profissionais se mobilizem perante as teorias e ações de suas práticas.

A integralidade do serviço só pode ser obtida em rede. Pode haver algum grau de integralidade focalizada quando uma equipe em um serviço de saúde, através de uma boa articulação de suas práticas consegue escutar e atender da melhor forma possível as necessidades de saúde trazidas por cada um. (CECÍLIO; MERHY, 2003, citado por CACHAPUZ, 2006, p. 45)

Apesar das dificuldades de atuação com esse público adolescente nos hospitais, seja pela falta de estudos específicos, seja por ambiente inapropriado, pela dificuldade de se fazer valer as diretrizes balizadoras da adolescência ou pelas próprias características dessa faixa etária, o psicólogo deve estar sempre disposto à oferecer assistência e se atualizar diante da temática, ofertando, assim, o melhor de seu serviço, dentro das condições possíveis do fazer psicológico. 


\section{Considerações Finais}

A adolescência, fase de transição entre vida infantil e adulta, é de suma importância para o ciclo vital do sujeito. Neste artigo, portanto, objetivouse relacionar esse período - a adolescência - com o atendimento hospitalar, bem como a atuação do profissional de Psicologia nesse contexto. Podemos perceber, ao longo do trabalho, que este âmbito ainda não se encontra bem desenvolvido e requer mais estudos e compreensão. Não existem ainda profissionais totalmente especializados e/ou capacitados o bastante para atendimento a esse público específico, seja na enfermaria ou no ambulatório, ambientes estes que não atendem especificamente às peculiaridades dessa etapa da vida, mesmo que haja esforço por parte da equipe que acolhe adolescentes. A criação de áreas de internação exclusivos à esta clientela, então, traria benefícios ao cuidado desses pacientes e maior conhecimento teóricoprático para a equipe que atua com a saúde juvenil.

Considerando, em particular, a atuação do psicólogo hospitalar junto aos adolescentes hospitalizados, bem como com seus familiares e equipe multiprofissional, este poderá auxiliar na maneira que esses agentes lidam com a hospitalização, com o processo saúde-doença, mediar as relações e informações entre essas personagens, além de permitir que externalizem suas emoções de acordo com seu desejo.

\section{Nota}

1. Termo da Psicanálise, onde o sujeito percebe-se como um ser faltoso, sustentando o simbólico de sua existência e constituindo sua realidade.

2. Utilizado por Lacan, explicitado em sua obra Seminário 1: os escritos técnicos de Freud (1979), para determinar um lugar simbólico, seja a lei, a linguagem, o inconsciente, que determina o sujeito.

3. Utilizado por Lacan, explicitado em sua obra Seminário 1: os escritos técnicos de Freud (1979), para determinar um lugar simbólico, seja a lei, a linguagem, o inconsciente, que determina o sujeito.

\section{Referências}

ABERASTURY, Arminda; KNOBEL, Maurício. Adolescência Normal: um enfoque psicanalítico. Porto Alegre. Artes médicas, 1981.

ALBERTI, Sonia. Esse sujeito adolescente. 3. ed. Rio de Janeiro: Rios Ambiciosos, 2009.

\section{O adolescente e o Outro. 3. ed. Rio de Janeiro: Zahar, 2010.}

ALMEIDA, Fabiane de Amorim; SABATÉS, Ana Llhonc. Enfermagem Pediátrica: a criança, o adolescente e sua família no hospital. São Paulo: Manole, 2008.

ALMEIDA, Inez Silva de; RODRIGUES, Benedita Maria Rêgo Deusdará; SIMÕES, Sonia Mara Faria. Hospitalização do adolescente. Revista da Sociedade Brasileira de Enfermaria Pediátrica, São Paulo, v. 7, n. 1, p. 3395, julho 2007.

ARIĖS, Phillippe. História social da criança e da família. 2. ed. Rio de Janeiro: Guanabara, 1986.
BRASIL. Constituição: República Federativa do Brasil. Brasília: Congresso Nacional, 1988.

Conselho Nacional dos Direitos da Crianca e do Adolescente. Resolução $\mathrm{n}^{\circ} 41$, de 13 de outubro de 1995. Direitos da criança e do adolescente hospitalizados. Brasília: Imprensa Oficial, 1995.

Estatuto da Criança e do Adolescente. Brasília, 1990.

Ministério da Saúde. Conceitos e definições em saúde. Rio de Janeiro, 1977.

Ministério da Educação e Saúde. Departamento de Saúde. Divisão de Organização Hospitalar. História e Evolução dos Hospitais. Rio de Janeiro, 1944.

BURD, Miriam. O Adolescente e a Experiência do Adoecer: o diabetes mellitus. Adolescência e Saúde, v. 3, n. 1, p. 12-17, Jan. 2006.

CACHAPUZ, Daniela Rosa. Psicologia Hospitalar: um olhar interdisciplinar no atendimento a crianças e adolescentes. Revista Brasileira de Psicologia Hospitalar, v. 9, n. 2 p. 44-67, 2006.

CAMPOS, Terezinha Calil Padis. Psicologia Hospitalar: a atuação do psicólogo em hospitais. São Paulo: EPU, 1995.

CHIATTONE, Heloísa Benevides Carvalho. A criança e a morte. In: ANGERAMI-CAMON, Valdemar Augusto. (org.). E a psicologia entrou no hospital. São Paulo: Pioneira Thomson Learning, 2003. Cap. 2, p. $69-146$. CURY, Munir. Estatuto da criança e do adolescente comentado: comentários jurídicos e sociais. 12. ed. São Paulo: Malheiros, 2013.

FONGARO, Maria Lúcia Hares; SEBASTIANI, Ricardo Werner. Roteiro de avaliação psicológica aplicada no hospital. In: ANGERAMI-CAMON, Valdemar Augusto. (org.). E a psicologia entrou no hospital. São Paulo: Pioneira Thomson Learning, 2003. Cap. 1, p. 5 - 68 .

FOUCAULT, Michel. Microfísica do poder. Rio de Janeiro: Graal, 1996. 1975. Doença mental e Psicologia. Rio de Janeiro: Tempo Brasileiro,

GUZMAN, Christine Ranier; CANO, Maria Aparecida Tedeschi. O adolescente e a hospitalização. Revista Eletrônica de Enfermagem, v. 2, n. 2, 2000. Disponível em: https://doi.org/10.5216/ree.v2i2.690. Acesso em: 03 de março de 2020 .

HONICKY, Marilise; SILVA, Rosanna Rita. O Adolescente e o Processo de Hospitalização: percepção, privação e elaboração. Psicologia Hospitalar. V. 7, n. 1, p. 44-67, 2009.

LACAN, Jacques. O Seminário - Livro 1: os escritos técnicos de Freud. Rio de Janeiro, Jorge Zahar, 1979.

NIGRO, Magdalena. Hospitalização: o impacto na criança, no adolescente e no psicólogo hospitalar. São Paulo: Casa do Psicólogo, 2004.

PINHEIRO, Tatiane da Rosa. Organização Hospitalar: públicos e complexidade. Seminário avançado em comunicação. São Leopoldo, RS: Universidade do Vale do Rio dos Sinos, 2005.

QUEIROZ, Lígia Bruni;AYRES, José Ricardo de Carvalho Mesquita; SAITO, Maria Ignez; MOTA, André. Aspectos históricos da institucionalização da atenção à saúde do adolescente no estado de São Paulo, 1970-1990. História, ciências e saúde - Manguinhos, Rio de Janeiro, v. 20, n. 1, Jan/Mar, 2013.

SAGGESE, Edson Guimarães. Adolescência e psicose: transformações sociais e os desafios da clínica. Rio de Janeiro: Companhia de Freud, 2001.

SANTOS, Claudia Tavares dos; SEBASTIANI, Ricardo Werner. Acompanhamento psicológico à pessoa portadora de doença crônica. In: ANGERAMI-CAMON, Valdemar Augusto. (org.). E a psicologia entrou no hospital. São Paulo: Pioneira Thomson Learning, 2003. Cap. 3, p. 147 -180 .

SIMONETTI, Alfredo. Manual de Psicologia Hospitalar: o mapa da doença. São Paulo: Casa do Psicólogo, 2004. 